\title{
Maladie et soins sous l'angle sociologique
}

\section{Jean Martin}

Membre de la rédaction

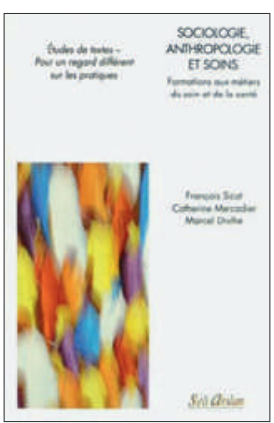

François Sicot, Catherine Mercadier, Marcel Drulhe

Sociologie, Anthropologie et Soins Formations aux métiers du soin et de la santé Paris: Seli Arslan; 2014. 254 pages. $38,80 \mathrm{CHF}$. ISBN 978-2-842-762O2-5
Traitant de sociologie de la médecine, des soins et des relations soigné-soignant, il s'agit d'une collection d'articles rassemblés par deux sociologues universitaires et une directrice des soins de centre hospitalier. 44 textes publiés au cours des 40 dernières années: trois peuvent être dits classiques (de L. Boltanski, I. Kenneth Zola, F. Loux), parus entre 1970 et 1974, 14 ont été publiés entre 1988 et 1999 et 27 depuis 2000. Ils l'ont été dans des revues diverses (dix dans Sciences sociales et santé), quelques-uns dans des ouvrages. La grande majorité sont d'auteurs français, quelques autres francophones et quelques anglophones.

Après une introduction, cinq chapitres : 1) Individu et société: la socialisation; 2) Expérience et sens de la maladie; 3) Soins et relations de soins; 4) L'organisation des soins; 5) Logiques professionnelles et logiques profanes. Chaque chapitre a sa propre introduction et se termine par une série de questions transversales - utiles dans un cadre de formation, qu'on soit en institution ou qu'il s'agisse d'étude personnelle. Les données précises des références mentionnées ne sont pas fournies en fin d'article (néanmoins, les moyens actuels permettront en général de retrouver ces sources). Pas d'index, mais on se souviendra qu'il ne s'agit pas d'un traité, mais d'un recueil visant à introduire les étudiants aux dimensions sociales, cas échéant familiales, et culturelles des carrières qu'ils embrassent. Le lecteur trouvera parfois une langue sociologique différente de celles des études de médecine ou de soins, maîtrisable sans difficultés toutefois.

Même si certains peuvent le regretter, «La question de la contractualisation des rapports sociaux est à l'ordre du jour. $\mathrm{Au}$ cours des trente dernières années, les sciences sociales en ont fait une figure centrale de l'évolution. La régulation contractuelle est partout, comme une réalité et comme une aspiration" (B. Bastard).

A noter deux textes sur la fin de vie et la mort, thème majeur aujourd'hui: de Maurice Bloch La mort et la conception de la personne et, de Nancy Kentish-Barnes, Mourir à l'heure du médecin - Décisions de fin de vie en réanimation. Extrait: «Dans ces services, deux types de mort prévalent. La première, naturelle, évolution ultime du processus pathologique. La seconde, produite et construite, est le fruit d'une décision de limitation ou d'arrêt des thérapeutiques.» Et de rappeler que plus de $70 \%$ des décès en France surviennent en hôpital et que $50 \%$ de ces morts hospitalières ont lieu dans les services de réanimation (services où les deux tiers des décès font suite à une décision de nature médicale). Est cité D. Sudnow: "Death is a decisional matter.» Il convient d'avoir ces chiffres à l'esprit dans certains débats sur l'idée qu'il faudrait laisser «la nature suivre son cours" (oubliant tant soit peu, soit dit en passant, que pour l'essentiel la médecine a pour but de contrecarrer et si possible éliminer les processus naturels - liés à des bactéries, virus, évolutions pathologiques, etc. - qui menacent la santé et la vie). Tout en forçant le trait, Kentish-Barnes présente les portraits-robots de deux types de services de réanimation: l'un hiérarchique, sous des médecins très directifs, mettant à l'écart infirmières et familles, où l'idée d'une réflexion éthique poussée ne fait pas partie de l'appareil conceptuel de l'équipe médicale; l'autre, différent en pratiquement tous les points, ou la collégialité et une démarche éthique sont au cœur du processus décisionnel. Quelques textes discutent l'irruption croissante des moyens électroniques dans la relation de soins.

Dans l'introduction du dernier chapitre: "Quand les hommes considèrent certaines situations comme réelles, elles sont réelles dans leur conséquence. Peu importe si d'un certain point de vue ils se trompent. Les documents socio-anthropologiques visent à expliciter certaines facettes des logiques profanes. La dimension conflictuelle que peut prendre la confrontation avec les logiques professionnelles n'exclut pas la négociation et l'aboutissement à des compromis raisonnables, satisfaisants pour chaque parti.»

En une période où l'accent est mis sur l'importance des sciences humaines et sociales («Medical Humanities») dans les études, un tel recueil est utile et bienvenu. On pourrait souhaiter que l'éventail de l'ouvrage s'étende au-delà de, pour l'essentiel, l'Europe occidentale - avec ses minorités culturelles toutefois, mais il s'agirait alors d'une autre entreprise, qui s'en irait vers des anthropologies exotiques, l'ethnomédecine voire l'ethnopsychiatrie. Pour la formation de base des professionnels, l'ouvrage dirigé par F. Sicot et coll. remplit son objectif. 